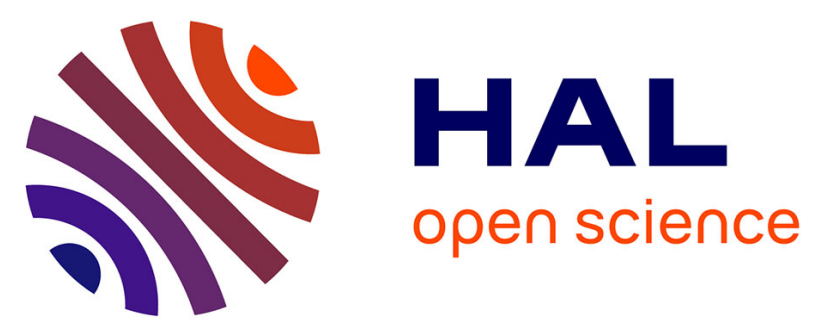

\title{
Benefits of a contralateral routing of signal device for unilateral Naída CI cochlear implant recipients
}

Isabelle Mosnier, Ghizlene Lahlou, Jonathan Flament, Nathalie Mathias, Evelyne Ferrary, Olivier Sterkers, Daniele Bernardeschi, Yann Nguyen

\section{- To cite this version:}

Isabelle Mosnier, Ghizlene Lahlou, Jonathan Flament, Nathalie Mathias, Evelyne Ferrary, et al.. Benefits of a contralateral routing of signal device for unilateral Naída CI cochlear implant recipients. European Archives of Oto-Rhino-Laryngology, 2019, 276 (8), pp.2205-2213. 10.1007/s00405-01905467-9 . hal-02385205

\section{HAL Id: hal-02385205 https://hal.sorbonne-universite.fr/hal-02385205}

Submitted on 29 Jun 2020

HAL is a multi-disciplinary open access archive for the deposit and dissemination of scientific research documents, whether they are published or not. The documents may come from teaching and research institutions in France or abroad, or from public or private research centers.
L'archive ouverte pluridisciplinaire HAL, est destinée au dépôt et à la diffusion de documents scientifiques de niveau recherche, publiés ou non, émanant des établissements d'enseignement et de recherche français ou étrangers, des laboratoires publics ou privés. 


\section{Benefits of a contralateral routing of signal device}

\section{for unilateral Naída $\mathrm{Cl}$ cochlear implant recipients}

Isabelle Mosnier 123 , Ghizlene Lahlou 45 , Jonathan

Flament 67 , Nathalie Mathias 8 , Evelyne Ferrary 64 , Olivier

Sterkers 64 , Daniele Bernardeschi 64 , Yann Nguyen 64

Affiliations

1 Sorbonne Université, Inserm, Unité de Réhabilitation chirurgicale mini-invasive robotisée de l'audition, Paris, France. isabelle.mosnier@aphp.fr

2 AP-HP, GHU Pitié-Salpêtrière, Service ORL, Otologie, Implants auditifs et chirurgie de la base du crâne, Paris, France. isabelle.mosnier@aphp.fr.

3 Unité Otologie, Implants auditifs et Chirurgie de la base du crâne, GH Pitié-Salpêtrière-Bâtiment Castaigne, 47-83 Boulevard de l'Hôpital, 75651, Paris Cedex 13, France. isabelle.mosnier@aphp.fr.

4 AP-HP, GHU Pitié-Salpêtrière, Service ORL, Otologie, Implants auditifs et chirurgie de la base du crâne, Paris, France.

5 Sorbonne Université, Institut Pasteur, Inserm, Unité de génétique et de physiologie de l'Audition, Paris, France.

6 Sorbonne Université, Inserm, Unité de Réhabilitation chirurgicale mini-invasive robotisée de l'audition, Paris, France.

7 Laboratoire Audika, Paris, France.

8 Advanced Bionics, Bron, France. 


\section{Abstract}

Purpose: Many bilaterally deaf adults are only able to receive one cochlear implant $(\mathrm{Cl})$, resulting in suboptimal listening performance, especially in challenging listening environments. Adding a contralateral routing of signal (CROS) device to a unilateral $\mathrm{Cl}$ is one possibility to alleviate these challenges. This study examined the benefit of such a CROS device.

Methods: Thirteen adult subjects with at least 6 months of $\mathrm{Cl}$ use, and no or limited benefit of a hearing instrument in the contralateral ear were included in the study. The perceived benefit of a CROS device in everyday listening environments was evaluated up to one year after initial fitting using several questionnaires. Speech intelligibility performance was determined using the French matrix sentence test in quiet and in two speech-in-noise setups and was followed for three months after CROS fitting.

Results: Subjects indicated high satisfaction with the practical usability of the CROS device and long-term device retention was high. Perceived benefits in everyday listening environments were reported. Formal speech intelligibility tests revealed statistically significant median improvements of $6.93 \mathrm{~dB} S \mathrm{SL}$ (Wilcoxon $Z=2.380, p=0.017$ ) in quiet and up to $8.00 \mathrm{~dB}$ SNR (Wilcoxon $Z=$ 2.366, $p=0.018)$ in noise. These benefits were accessible immediately without a need for prolonged acclimatization.

Conclusions: Subjective satisfaction and device retention as well as speech intelligibility benefits in quiet and in noise prove the CROS device to be a 
valuable addition to a unilateral $\mathrm{Cl}$ in cases of bilateral deafness where bilateral implantation is not an option. 


\section{Introduction}

Cochlear implantation has become the standard auditory rehabilitation for adults and children with bilateral severe to profound hearing loss. Although several studies show the benefits of bilateral cochlear implantation with respect to sound localisation and listening in noise [1-5], individual results vary and the few available cost-utility analysis in adult recipients reports provide insufficient evidence to draw definite conclusions [6, 7]. Consequentially, bilateral implantation, especially in adults, is currently not funded in many healthcare systems. Therefore, many bilaterally deaf adults receive only one cochlear implant $(\mathrm{Cl})$. Even if bilateral implantation is reimbursed in adults, medical reasons might prevent implantation of the second side. Additionally, patients may choose not to undergo a second $\mathrm{Cl}$ surgery, for example because they are concerned about surgery risks or because they wish to preserve that ear for future treatment options.

Irrespective of the reason preventing the second implantation, these bilaterally deaf unilaterally implanted subjects will continue to experience limitations due to the head shadow effect. Audibility of sound sources located away from the implanted ear is reduced resulting for example in impaired speech intelligibility in noise and reduced awareness of the surrounding sounds.

To alleviate these difficulties, one treatment option is a contralateral routing of signal (CROS) device, consisting of a microphone placed on the non-hearing/ implanted ear. Signals from that side are picked up and transmitted to the hearing/implanted side. 
While long established in the hearing aid community [8], CROS devices in combination with unilateral Cls have only recently been investigated [9-18]. These studies consistently demonstrated a speech intelligibility benefit provided by the CROS device when the target speech source is located on the side of the non-implanted ear. When noise is located on the side of the nonimplanted ear, a decrease in speech intelligibility was observed, the degree of which varies depending on the exact test setup.

In addition to acute speech intelligibility testing, chronic data have been collected, with a maximum take home of two weeks. While Weder [14] did not show a significant perceived improvement after chronic trials, a subjective benefit was observed in other studies on the Abbreviated Profile of Hearing Aid Benefit (APHAB, [19]) $[10,11]$, in the Speech subscale of the abbreviated Speech Spatial and Qualities of Hearing Scale (SSQ12, [20]) [16] and in the Spatial subscale of the Speech Spatial and Qualities of Hearing Scale (SSQ, [21]) [10]. However in the Guevara study which evaluated a CROS device with a wire connection [11], only two of the eight subjects were still using their CROS device after six months, citing difficulties in noisy environments and trouble with the connecting wire.

The Phonak Naída Link CROS device investigated in the current study provides a wireless solution, designed to improve wearing comfort. Additionally, the device carries a mute button to silence input from the CROS side in noisy listening environments. Both features have previously been reported as useful 
enhancements to the tested prototype devices $[11,13,14]$. The device can be used with the Advanced Bionics Naída Cl Q70 and Q90 sound processors.

Our study focusses on the long-term evaluation of perceived everyday benefits of using the CROS device. Subjects were followed closely for 3 months after fitting of the CROS device using measures of real life benefit and subjective satisfaction as well as repeated speech intelligibility testing. A one-year followup questionnaire evaluated the long-term retention rate and satisfaction with the CROS device.

\section{Materials and Methods}

A prospective, single centre, within-subjects repeated-measures design was chosen for this study. ') $v$

\subsection{Study Population}

Thirteen adult subjects were identified from the clinic's database. All subjects were implanted with an Advanced Bionics Cll or HiRes90k cochlear implant for at least six months and had used the Naída Cl Q70 sound processor for at least three months prior to testing. Three subjects clinically used a hearing aid in the contralateral ear, with limited benefit (defined as $<20 \%$ monosyllabic words in quiet). Two subjects were implanted in the contralateral ear but did not use the second $\mathrm{Cl}$ due perceived to lack of benefit. Detailed subject information is provided in table 1. 


\subsection{Device Fitting}

The most recent Advanced Bionics sound processors, the Naída CI Q70 and Q90, have the ability to communicate wirelessly with another Naída $\mathrm{Cl}$ processor, or with some Phonak hearing instrument models, including a CROS device. The Naída Link CROS device consists of a microphone, radio transmitter and battery worn on the unilateral $\mathrm{Cl}$ recipient's non-implanted ear. The microphone signal from the CROS device is transmitted wirelessly to the Naída $\mathrm{Cl}$ sound processor and mixed with the microphone signal from the implanted side with a mixing ratio of 50:50 before being coded by the sound processor.

In addition to the CROS device, a loaner Naída $\mathrm{Cl}$ processor was used for the duration of the study. The loaner sound processor was fitted with each subject's clinical program, according to the clinic's standard fitting routine and no changes were made to the fitting parameters. The Advanced Bionics

SoundWave 3.1 fitting software was used, which allows the activation of a HiBAN (Hearing Instrument Body Area Network) link between the $\mathrm{Cl}$ processor and the Naída CROS device. The CROS device is an out-of-the-box solution and works automatically with the Naída $\mathrm{Cl}$ processor without the need for any additional fitting. Subjects were counselled on use of the mute button which allows them to easily disable input from the CROS device in situations where it would enhance unwanted noise rather than speech. 


\subsection{Subjective evaluation}

Three questionnaires were used to record each subject's self-assessment of their hearing abilities as well as their satisfaction with the CROS device:

1) The Abbreviated Profile of Hearing Aid Benefit (APHAB; [19]), a 24-item selfassessment inventory, requires subjects to report the amount of trouble they experience with communication in various everyday situations. The APHAB includes four subscales: Ease of communication (EC), Reverberation (RV), Background noise (BN), and Aversiveness (AV). Scores are given on a scale from A (I always experience this) to $G$ (I never experience this). A percentage score from $1 \%$ to $99 \%$ is assigned to each category to yield a mean percentage for each subsection.

2) The abbreviated Speech Spatial Qualities Questionnaire (SSQ12, [20]) requires subjects to rate their listening abilities on a Likert scale from 1 (not at all) to 10 (perfectly). The SSQ12 includes three sub scales relating to aspects of speech, spatial and other qualities of hearing.

3) An adapted version of the Auditory Performance and Satisfaction Scale for Single-Sided Deafness (APS-SSD, [18, 22]) focuses on specific situations encountered in real life where a CROS device may be beneficial, grouped into three categories: hearing at home, hearing at work or school, and hearing in social situations. Each situation is rated on a scale from 0 (Can function fine) to 6 (Cannot function at all). It additionally contains a category on the satisfaction with and usability of the CROS device (see Electronic Supplementary Material). 


\subsection{Speech perception tests}

Speech intelligibility was measured in quiet and noise in a sound treated room using the French Matrix test (Framatrix, Auritec, Hamburg, Germany, [23]). Subjects were asked to repeat semantically unpredictable sentences with a fixed structure: name, verb, number, common name, color. Prior to testing, at least one practice list of 20 sentences for testing in quiet, and two practice lists for testing in noise were presented to the subject to avoid training effects. For testing in quiet, the speech recognition threshold (i.e. speech level required for $50 \%$ word intelligibility) was measured in $\mathrm{dB}$ SPL by adaptively adjusting the signal level. Speech was presented from - $90^{\circ}$ azimuth, on the CROS side. For testing in noise, the speech reception threshold (SRT; i.e. signalto-noise-ratio (SNR) required for 50\% word intelligibility) was measured in $\mathrm{dB}$ SNR by adaptively adjusting the signal level while stationary speech-shaped noise was fixed at $65 \mathrm{~dB}$. Noise was presented from $+90^{\circ}$ azimuth on the $\mathrm{Cl}$ side, while speech was presented either from $-90^{\circ}$ azimuth (CROS side) or from $0^{\circ}$ azimuth (front). The two conditions were tested in random order. All loudspeakers were positioned at $1 \mathrm{~m}$ distance from the subject's head. In all test conditions, subjects were tested with and without the CROS device in random order. Lower speech recognition thresholds as well as lower SRTs indicate better performance. 


\subsection{Measurement schedule}

Subjects were invited to the clinic for four appointments. An overview of the study schedule is provided in table 2 . At baseline, all subjects received a loaner Naída $\mathrm{Cl}$ processor, fitted with their clinical everyday program(s), and the CROS device. Subjects were tested in quiet and noise with the Naída $\mathrm{Cl}$ processor with and without the CROS device at the baseline, 1 month and 3 months appointments. The CROS device was removed at the 3 months appointment and subjects used the Naída $\mathrm{Cl}$ processor only for a further two weeks. Subjects were asked to complete questionnaires at each visit regarding their recent listening configuration (Naída $\mathrm{Cl}$ processor alone or with the CROS device). At the last visit, the loaner Naída $\mathrm{Cl}$ processor and the CROS device were returned and subjects were given the option to receive the CROS device free of charge once the appropriate market certification was obtained. All subjects were provided with a CROS device after completing the study. After approximately 1 year, these subjects were provided with a follow-up questionnaire evaluating device retention as well as long-term satisfaction with the CROS.

\subsection{Statistical analysis}

Statistical analyses were performed using Statistica 12 software (TIBCO Software Inc., Palo Alto, USA) with a level of significance set at 0.05. Due to the low N, non-parametric analyses were chosen. 


\subsubsection{Speech perception tests}

Significance of the CROS benefit (i.e. difference in performance between $\mathrm{Cl}$ only and $\mathrm{Cl}+\mathrm{CROS}$ condition) was tested using the Wilcoxon signed rank statistic. Differences in performance over time as well as differences in CROS benefit over time were analysed using Friedman ANOVA followed by post-hoc Wilcoxon signed rank tests. Bonferroni corrections were applied where necessary.

\subsubsection{Subjective evaluation}

Analysis of the subjective feedback collected via questionnaires focused on the respective subscales. The two $\mathrm{Cl}$ only timepoints (baseline and 3.5 months) and the two $\mathrm{Cl}+$ CROS timepoints (1 month and 3 months) were combined and contrasted using Wilcoxon signed rank tests.

\section{Results}

Three of the 13 originally recruited subjects chose to withdraw from the study after the baseline or 1 month visit. Subject 11 withdrew from the study for personal reasons. Subjects 4 and 9 clinically used a HA in the contralateral ear and discontinued use of the CROS device in favour of their clinical HA.

Of remaining ten subjects, eight performed speech tests in quiet. The remaining two subjects were unable to perform the French matrix test. In 
noise, one further subject was unable to complete the matrix test at the baseline appointment resulting in seven complete datasets.

At baseline, 1, 3 and 3.5 months, questionnaires were completed by all ten subjects. At 1-year follow-up, questionnaires were returned by eight subjects.

\subsection{Subjective evaluation}

To analyze the subjective feedback, responses from the baseline and 3.5 months appointments and responses from the 1 month and 3 months appointments were combined to form two categories: $\mathrm{Cl}$ only and $\mathrm{Cl}+\mathrm{CROS}$. The two categories were then compared regarding each questionnaire's respective subscales as well as one overall score for each questionnaire. These results are displayed in figure 1.

For the APHAB and SSQ12 questionnaires, no significant differences between the $\mathrm{Cl}$ only and $\mathrm{Cl}+\mathrm{CROS}$ categories were found for any of the respective subscales or the overall scores. For the experience portion of the adapted APSSSD questionnaire, significant differences were found for the 'Social' and 'General' subscales but not for the remaining two subscales or the overall score. Results of the Wilcoxon signed rank statistic for all questionnaires is summarized in table 3.

The satisfaction portion of the adapted APS-SSD questionnaire revealed high satisfaction with several aspects of the CROS device itself indicated by median ratings lower than 3 (figure 2a). Responses from eight subjects who provided 
answers at the 1 month, 3 months and 1 year appointments were combined for each item.

In addition, the average score across all items of the APS-SSD satisfaction portion was analyzed regarding changes across time (see figure $2 \mathrm{~b}$ ). No statistically significant difference in average satisfaction score was found between the different timepoints ( 1 month, 3 months and 1 year).

The questionnaire further revealed that the CROS device was used most of the time with median usage times of $11.5 \mathrm{~h}$ ( 1 month), $11 \mathrm{~h}$ ( 3 months) and $10.25 \mathrm{~h}$ (1 year). When asked for the preferred device configuration by the end of the study, nine out of the ten subjects who completed the study clearly preferred the CROS device while the remaining subject stated no preference. One year after the end of the study, only one out of eight responses reported a preference for the $\mathrm{Cl}$ alone.

\subsection{Speech intelligibility}

Median speech perception scores in quiet (Fig. 3) as well as the two noise scenarios $\mathrm{S}_{\mathrm{CROS}} \mathrm{N}_{\mathrm{Cl}}$ (Fig. 4a) and $\mathrm{SoN}_{\mathrm{Cl}}$ (Fig.4b) are presented in figures 3 and 4 for the baseline, 1 month and 3 months appointments.

In quiet, the median differences in performance between the $\mathrm{Cl}$ only and $\mathrm{Cl}+$ CROS conditions were 6.93 dB SPL, 4.15 dB SPL and 3.38 dB SPL at the baseline, 1 month and 3 months appointments. 
In $\mathrm{S}_{\mathrm{CROS}} \mathrm{N}_{\mathrm{Cl}}$, the median differences in performance between the $\mathrm{Cl}$ only and $\mathrm{Cl}+$ CROS conditions were 6.15 dB SNR, 7.75 dB SNR and 8.00 dB SNR at the baseline, 1 month and 3 months appointments. In $S_{C R O S} N_{C l}$, the median differences in performance between the $\mathrm{Cl}$ only and $\mathrm{Cl}+\mathrm{CROS}$ conditions were 2.10 dB SNR, $2.00 \mathrm{~dB}$ SNR and $2.65 \mathrm{~dB}$ SNR at the baseline, 1 month and 3 months appointments. All differences were found to be statistically significant (Wilcoxon signed rank test, statistics reported in table 4).

Furthermore, Friedman analysis revealed that overall performance improved across the appointments for $\mathrm{Cl}$ only in quiet $\left(\mathrm{x}^{2}(2)=10.75, \mathrm{p}=.005\right)$, for $\mathrm{Cl}+$ CROS in quiet $\left(x^{2}(2)=7.75, p=.021\right)$, for $\mathrm{Cl}$ only in $\mathrm{S}_{\mathrm{CROS}} \mathrm{N}_{\mathrm{Cl}}\left(\mathrm{x}^{2}(2)=8.00, \mathrm{p}=\right.$. 018), for $\mathrm{Cl}+$ CROS in $\mathrm{S}_{C R O S} \mathrm{~N}_{\mathrm{Cl}}\left(\mathrm{x}^{2}(2)=7.14, \mathrm{p}=.028\right)$ and for $\mathrm{Cl}$ only in $\mathrm{S}_{\mathrm{O}} \mathrm{N}_{\mathrm{Cl}}$ $\left(x^{2}(2)=7.14, p=.028\right)$. Performance for $\mathrm{Cl}+\mathrm{CROS}$ in $\mathrm{S}_{0} \mathrm{~N}_{\mathrm{CI}}\left(\mathrm{x}^{2}(2)=3.71, \mathrm{p}=\right.$. 156) as well as the CROS benefit in quiet $\left(x^{2}(2)=1.35, p=.508\right)$, in $S_{C R O S} N_{C I}$ $\left(\mathrm{x}^{2}(2)=.28, \mathrm{p}=.867\right)$ and in $\mathrm{S}_{0} \mathrm{~N}_{\mathrm{Cl}}\left(\mathrm{x}^{2}(2)=4.96, \mathrm{p}=.084\right)$ remained stable across the appointments.

\section{Discussion}

Three subjects withdrew throughout the course of the study. Subject 11 withdrew for personal reasons and reported satisfaction with the CROS device. Subjects 4 and 9 stated higher satisfaction with their clinical HA as reason for 
their discontinuation. While both patients only achieve limited speech intelligibility with their $\mathrm{HA}$ alone ( $6 \%$ and $18 \%$ monosyllabic words in quiet), both patients receive a sizeable bimodal benefit of $23 \%$ and $30 \%$ respectively, suggesting that bimodal benefit rather than contralateral speech scores may be a more suitable criterion for CROS candidacy. Conversely, subject 3 who also received $30 \%$ bimodal benefit with the clinical HA reported high satisfaction with the CROS device compared to the clinical HA.

This indicates that CROS candidacy and the acceptance of CROS in bimodal $\mathrm{Cl}$ users depend to a large extend on personal factors and cannot be predicted by speech intelligibility with the HA or bimodal benefit alone. Since the Naída Link CROS device does not require personalized fitting and the Naída $\mathrm{Cl}$ processor is easily activated for use with the CROS device, a trial phase with the CROS device could be realized within the clinical routine to determine the best rehabilitation option (CROS or $\mathrm{HA}$ ) in bimodal $\mathrm{Cl}$ users with limited bimodal benefit or limited contralateral speech intelligibility.

The subjective evaluation revealed few significant changes. Especially the validated, general questionnaires $A P H A B$ and SSQ12 proved not sensitive enough to capture CROS benefits by showing no significant changes in any of the subscales or the overall score. Considering that these questionnaires were designed for HA users and are not geared towards listening environments or situations where a CROS benefit can be expected, the lack of significance is not surprising, even though Grewal et al [10] and Guevara et al [11] were able to demonstrate a significant CROS benefit in the APHAB questionnaire and Grewal 
et al. [10] and Dwyer et al. [16] in the SSQ and SSQ12 respectively. The dedicated adapted APS-SSD questionnaire did show significant improvements in the 'Social' and 'General' subscale. The remaining subscales 'Home' and 'Work/School' as well as the overall score did not reveal significant changes, indicating that even dedicated questionnaires might not be sensitive enough to capture CROS benefits. Subjects were asked to fill in the questionnaires at each appointment independently without access to their previous ratings. Providing subjects access to their previous responses, therefore enabling a comparative rating, may have improved the questionnaires sensitivity to subtle changes. The high preference for the $\mathrm{Cl}+\mathrm{CROS}$ configuration, immediately after the study as well as after one year, indicates the usefulness of and perceived benefit provided by the CROS device nonetheless.

The usefulness and perceived benefit despite the lack of significant improvements in the questionnaires is further supported by the free feedback provided by subjects. Several subjects indicated feeling more balanced with the CROS device, being more aware of surrounding sounds and missing the CROS immediately if the batteries run out. Notably, several subjects also indicated improved localisation abilities with the CROS device. While localisation performance with the CROS device was not investigated in this study, by design the device does not provide binaural auditory input and can therefore not be expected to enable or improve localisation abilities as confirmed by previous studies $[14,15]$. We therefore suggest that subjects 
indicating improved localisation abilities rather refer to improved awareness of surrounding sounds, especially sounds originating towards the unimplanted ear. Speech intelligibility tests in quiet and in noise expectedly yielded good results in favourable conditions: median improvements of up to $6.9 \mathrm{~dB}$ and $8.0 \mathrm{~dB}$ with the CROS device when speech is presented from the CROS side in quiet an in noise respectively and up to $2.7 \mathrm{~dB}$ in noise when speech is presented from the front.

In many cases, direct comparison of these outcomes to previously published studies is precluded by the use of different speech materials as well as different test setups in the respective studies. While Wimmer et al. [15] used comparable speech material (German matrix sentence test [24]), the CROS device tested consisted of a directional microphone rather than the omnidirectional microphone tested here, complicating direct comparisons. Ernst et al. [17] however used comparable speech material and included the $\mathrm{S}_{\mathrm{CROS}} \mathrm{N}_{\mathrm{Cl}}$ condition reported here allowing a direct comparison: their reported CROS benefit (median difference) of $7.23 \mathrm{~dB}$ s compares quite well to the 8.0 $\mathrm{dB}$ found here.

Unfavourable conditions where speech is presented from the $\mathrm{Cl}$ side and noise from the CROS side or diffusely were not included in this evaluation. In these conditions, the CROS device adds additional noise and performance is expected to decrease as has previously been shown $[9,12,13,16]$. To avoid this performance decrease in unfavourable listening conditions, the CROS device 
tested here features a mute button which can be used to silence undesired input from the CROS side.

The overall performance increased significantly over time in almost all listening conditions. This could either indicate subjects' general speech intelligibility improving over time or the subjects becoming more familiar with the used speech test material. The subjects included in this study have used their $\mathrm{Cl}$ for at least 10 months with an average $\mathrm{Cl}$ use of 5 years and 3 months, leading us to exclude a general learning effect as the cause of the improved performance over time. The French matrix sentence test used in this study is not routinely used in the clinic, therefore most subjects were not familiar with this closed set speech material. Although the most pronounced improvement is seen during the first two test lists and therefore two practice lists are generally considered sufficient to avoid training effects, long-term training effects using closed-set speech material have been shown for the German matrix sentence test [25]. We therefore suggest a training/learning effect to have caused the overall performance improvement over time.

In contrast to the overall performance, CROS benefits remained stable over time in all listening conditions. No acclimatisation or learning was required, subjects benefitted from the CROS device immediately after fitting.

\section{Conclusion}


The Naída Link CROS device was designed as an addition to a unilateral $\mathrm{Cl}$ in cases of bilateral deafness when bilateral implantation is not an option. It was shown to increase speech intelligibility for speech sources located toward the unimplanted side. Subjects reported satisfaction with the CROS device itself and perceived benefits in their everyday listening environments such as increased sound awareness. The high long-term retention rate further confirms the CROS device to be a valuable addition to a unilateral $\mathrm{Cl}$.

\section{Compliance with ethical standards}

Conflict of interest: The authors declare that they have no conflict of interest. Ethical approval: All study procedures were approved by the ethical committee, 'Comité de Protection des Personnes Sud-Est V' and the French competent authority, ANSM (Agence Nationale de Sécurité du Médicament et des produits de santé) and were conducted in accordance with the ethical standards defined by the Declaration of Helsinki. The study was registered as N NCT03078920 at www.clinicaltrials.gov.

Informed consent: Informed consent was obtained from all individual participants included in the study. 


\section{References}

1. De Seta D, Nguyen Y, Vanier A, et al (2016) Five-Year Hearing Outcomes in Bilateral Simultaneously Cochlear-Implanted Adult Patients. Audiol Neurootol 21:261-267 . doi: 10.1159/000448582

2. Laske RD, Veraguth D, Dillier N, et al (2009) Subjective and objective results after bilateral cochlear implantation in adults. Otol Neurotol Off Publ Am Otol Soc Am Neurotol Soc Eur Acad Otol Neurotol 30:313-318 . doi: 10.1097/MAO.0b013e31819bd7e6

3. Mosnier I, Sterkers O, Bebear J-P, et al (2009) Speech performance and sound localization in a complex noisy environment in bilaterally implanted adult patients. Audiol Neurootol 14:106-114 . doi: 10.1159/000159121

4. Smulders YE, van Zon A, Stegeman I, et al (2016) Comparison of Bilateral and Unilateral Cochlear Implantation in Adults: A Randomized Clinical Trial. JAMA Otolaryngol Head Neck Surg 142:249-256 . doi: 10.1001/ jamaoto.2015.3305

5. van Schoonhoven J, Sparreboom M, van Zanten BGA, et al (2013) The effectiveness of bilateral cochlear implants for severe-to-profound deafness in adults: a systematic review. Otol Neurotol 34:190-198

6. Chen JM, Amoodi H, Mittmann N (2014) Cost-utility analysis of bilateral cochlear implantation in adults: a health economic assessment from the perspective of a publicly funded program. Laryngoscope 124:1452-1458 . doi: 10.1002/lary.24537

7. Crathorne L, Bond M, Cooper C, et al (2012) A systematic review of the effectiveness and cost-effectiveness of bilateral multichannel cochlear implants in adults with severe-to-profound hearing loss. Clin Otolaryngol 37:342-354 . doi: 10.1111/coa.12011

8. Ryu N-G, Moon IJ, Byun H, et al (2015) Clinical effectiveness of wireless CROS (contralateral routing of offside signals) hearing aids. Eur Arch Otorhinolaryngol 272:2213-2219 . doi: 10.1007/s00405-014-3133-0

9. Arora R, Amoodi H, Stewart S, et al (2013) The addition of a contralateral routing of signals microphone to a unilateral cochlear implant system. A prospective study in speech outcomes. Laryngoscope 123:746-751 . doi: 10.1002/lary.23367

10. Grewal AS, Kuthubutheen J, Smilsky K, et al (2015) The role of a new contralateral routing of signal microphone in established unilateral cochlear implant recipients. Laryngoscope 125:197-202 . doi: 10.1002/lary. 24873 
11. Guevara N, Grech C, Gahide I, Gallego S (2015) Assessment of the contralateral routing of signal system in unilateral cochlear implantation. Clin Otolaryngol 40:535-544 . doi: 10.1111/coa.12404

12. Taal CH, van Barneveld DCPBM, Soede W, et al (2016) Benefit of contralateral routing of signals for unilateral cochlear implant users. J Acoust Soc Am 140:393 . doi: 10.1121/1.4955307

13. van Loon MC, Goverts ST, Merkus P, et al (2014) The addition of a contralateral microphone for unilateral cochlear implant users: not an alternative for bilateral cochlear implantation. Otol Neurotol Off Publ Am Otol Soc Am Neurotol Soc Eur Acad Otol Neurotol 35:e233-239 . doi: 10.1097/MAO.0000000000000461

14. Weder S, Kompis M, Caversaccio M, Stieger C (2015) Benefit of a contralateral routing of signal device for unilateral cochlear implant users. Audiol Neurootol 20:73-80 . doi: 10.1159/000363212

15. Wimmer W, Kompis M, Stieger C, et al (2017) Directional Microphone Contralateral Routing of Signals in Cochlear Implant Users: A WithinSubjects Comparison. Ear Hear 38:368-373 . doi: 10.1097/AUD. 0000000000000412

16. Dwyer RT, Kessler D, Butera IM, Gifford RH (2018) Contralateral Routing of Signal Yields Significant Speech in Noise Benefit for Unilateral Cochlear Implant Recipients. J Am Acad Audiol. doi: 10.3766/jaaa.17117

17. Ernst A, Baumgärtel RM, Diez A, Battmer R-D (2019) Evaluation of a wireless Contralateral Routing of Signal (CROS) device with the Advanced Bionics Naída Cl Q90 sound processor. Cochlear Implants Int). doi: 10.1080/14670100.2019.1586151

18. Snapp HA, Hoffer ME, Spahr A, Rajguru SM (2018) Application of wireless contralateral routing of signal in unilateral cochlear implant users with bilateral profound hearing loss. J Am Acad Audiol doi: 10.3766/jaaa.17121

19. Cox RM, Alexander GC (1995) The abbreviated profile of hearing aid benefit. Ear Hear 16:176-186

20. Noble W, Jensen NS, Naylor G, et al (2013) A short form of the Speech, Spatial and Qualities of Hearing scale suitable for clinical use: the SSQ12. Int J Audiol 52:409-412 . doi: 10.3109/14992027.2013.781278

21. Gatehouse S, Noble W (2004) The Speech, Spatial and Qualities of Hearing Scale (SSQ). Int J Audiol 43:85-99 
22. Schafer EC, Baldus N, D'Souza M, et al (2013) Behavioral and Subjective Performance with Digital CROS/BiCROS Hearing Instruments. J Acad Rehabil Audiol 46:62-93

23. Jansen S, Luts H, Wagener KC, et al (2012) Comparison of three types of French speech-in-noise tests: a multi-center study. Int J Audiol 51:164173 . doi: 10.3109/14992027.2011.633568

24. Wagener K, Kühnel V, Kollmeier B (1999) Entwicklung und Evaluation eines Satztests für die deutsche Sprache I: Design des Oldenburger Satztests. Zeitschrift Für Audiologie/Audiological Acoustics 38:4-15

25. Schlueter A, Lemke U, Kollmeier B, Holube I (2016) Normal and TimeCompressed Speech: How Does Learning Affect Speech Recognition Thresholds in Noise? Trends Hear. doi: 10.1177/2331216516669889 


\section{Tables}

\section{Table 1 Detailed subject demographics}

\begin{tabular}{|c|c|c|c|c|c|c|c|c|}
\hline $\begin{array}{l}\text { Subje } \\
\text { ct }\end{array}$ & $\begin{array}{c}\mathrm{Ag} \\
\mathrm{e}\end{array}$ & $\begin{array}{l}\text { Gen } \\
\text { der }\end{array}$ & Etiology & $\begin{array}{l}\text { Impl } \\
\text { ant } \\
\text { Side }\end{array}$ & $\begin{array}{l}\text { Duration of } \mathrm{Cl} \\
\text { experience } \\
\text { (yrs/mos) }\end{array}$ & $\begin{array}{c}\text { Contralateral HL } \\
\text { (avg. PTA @ 0.5, } \\
1,2,4 \mathrm{kHz})\end{array}$ & $\begin{array}{l}\text { Regular } \\
\text { HI use } \\
\text { contralat } \\
\text { eral }\end{array}$ & Note \\
\hline 1 & 76 & $\mathrm{~m}$ & $\begin{array}{l}\text { meningitis, } \\
\text { otosclerosis }\end{array}$ & l & $1 / 2$ & 130 & no & \\
\hline 2 & 65 & $f$ & meningitis & $r$ & $7 / 3$ & 130 & no & \\
\hline 3 & 62 & $\mathrm{~m}$ & $\begin{array}{l}\text { Menière's } \\
\text { disease }\end{array}$ & l & $0 / 10$ & 85 & yes & $\mathrm{HA}, 0 \% \mathrm{WiQ}$ \\
\hline 4 & 69 & $\mathrm{~m}$ & $\begin{array}{l}\text { congenital } \\
\text { syphilis }\end{array}$ & l & $0 / 10$ & 92.5 & yes & $\mathrm{HA}, 6 \% \mathrm{WiQ}$ \\
\hline 5 & 67 & $f$ & otosclerosis & $r$ & $6 / 4$ & 123.75 & no & \\
\hline 6 & 59 & $\mathrm{~m}$ & $\begin{array}{l}\text { chronic otitis } \\
\text { media }\end{array}$ & $r$ & $7 / 6$ & 130 & no & \\
\hline 7 & 55 & $f$ & familial & l & $1 / 6$ & 113.75 & no & \\
\hline 8 & 56 & $f$ & hydrocephalus & $r$ & $1 / 1$ & 130 & yes & $\mathrm{Cl}$, non-user \\
\hline 9 & 51 & $f$ & unknown & $r$ & $7 / 0$ & 106.25 & yes & $\mathrm{HA}, 18 \% \mathrm{WiQ}$ \\
\hline 10 & 22 & $f$ & unknown & l & $6 / 8$ & 130 & no & \\
\hline 11 & 57 & $f$ & $\begin{array}{l}\text { familial, } \\
\text { otosclerosis }\end{array}$ & l & $8 / 10$ & 92.5 & yes & $\mathrm{Cl}$, non-user \\
\hline 12 & 50 & $f$ & $\begin{array}{l}\text { auto-immune } \\
\text { disease }\end{array}$ & l & $11 / 1$ & 96.25 & no & \\
\hline 13 & 63 & $\mathrm{~m}$ & $\begin{array}{l}\text { trauma, TB } \\
\text { fracture }\end{array}$ & $r$ & $8 / 6$ & 103.75 & no & \\
\hline
\end{tabular}

$\mathrm{HL}=$ hearing loss, $\mathrm{HI}=$ hearing instrument, $\mathrm{HA}=$ hearing aid, $\mathrm{TB}=$ temporal bone, $\mathrm{WiQ}=$ contralateral monosyllabic word score in quiet (Lafon lists)

Shaded rows indicate subjects who withdrew from the study 
Table 2 Study visits and procedures in chronological order

\begin{tabular}{|c|c|c|}
\hline Visit & Speech Test & Questionnaire \\
\hline baseline & 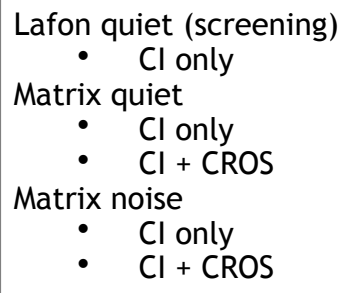 & $\begin{array}{l}\text { SSQ12 } \\
\bullet \\
\begin{array}{c}\text { APHAB } \\
\bullet\end{array} \\
\end{array}$ \\
\hline \multicolumn{3}{|c|}{ chronic experience $\mathrm{Cl}+\mathrm{CROS}$} \\
\hline 1 month & $\begin{array}{l}\text { Matrix quiet } \\
: \mathrm{Cl} \text { only } \\
: \mathrm{Cl}+\mathrm{CROS} \\
\text { Matrix noise } \\
: \mathrm{Cl} \text { only } \\
-\mathrm{Cl}+\text { CROS }\end{array}$ & $\begin{array}{ll}\begin{array}{l}\text { SSQ12 } \\
\bullet \\
\text { APHAB }\end{array} & \mathrm{Cl}+\text { CROS } \\
\stackrel{\bullet}{C} & \mathrm{Cl}+\text { CROS } \\
\text { APS-SSD } & \\
\bullet & \mathrm{Cl}+\text { CROS }\end{array}$ \\
\hline \multicolumn{3}{|c|}{ chronic experience $\mathrm{Cl}+\mathrm{CROS}$} \\
\hline 3 months & $\begin{array}{l}\text { Matrix quiet } \\
: \mathrm{Cl} \text { only } \\
: \mathrm{Cl}+\mathrm{CROS} \\
\text { Matrix noise } \\
: \mathrm{Cl} \text { only } \\
: \mathrm{Cl}+\text { CROS }\end{array}$ & $\begin{array}{l}\text { SSQ12 } \\
\stackrel{C}{C} \mathrm{Cl}+\text { CROS } \\
\text { APHAB } \\
\stackrel{\bullet}{\bullet} \mathrm{Cl}+\text { CROS } \\
\text { APS-SSD } \\
\mathrm{Cl}+\text { CROS }\end{array}$ \\
\hline \multicolumn{3}{|c|}{ chronic experience $\mathrm{Cl}$ only } \\
\hline 3.5 months & & $\begin{array}{cc}\text { SSQ12 } & \\
\bullet & \mathrm{Cl} \text { only } \\
\text { APHAB } & \\
\bullet & \mathrm{Cl} \text { only } \\
\text { APS-SSD (subset) } \\
\qquad \quad \text { Cl only }\end{array}$ \\
\hline \multicolumn{3}{|c|}{ chronic experience $\mathrm{Cl}+\mathrm{CROS} / \mathrm{Cl}$ only (depending on subject's choice) } \\
\hline 1 year & & $\begin{array}{l}\text { APS-SSD (subset) } \\
\qquad \quad \mathrm{Cl}+\mathrm{CROS}\end{array}$ \\
\hline
\end{tabular}


Table 3 Results of Wilcoxon signed rank statistic for APHAB, SSQ12 and APS-SSD questionnaires. Grey shading indicates statistical significance.

\begin{tabular}{|c|c|c|c|}
\hline & & $\mathrm{z}$ & $\mathrm{p}$ \\
\hline \multirow{5}{*}{$\begin{array}{c}\text { AP } \\
\text { HA } \\
B\end{array}$} & Ease of Communication & 0.296 & 0.767 \\
\hline & Background Noise & 0.764 & 0.445 \\
\hline & Reverberation & 0.140 & 0.889 \\
\hline & Aversiveness & 0.153 & 0.878 \\
\hline & Global & 0.357 & 0.721 \\
\hline \multirow{4}{*}{$\begin{array}{c}\text { SS } \\
\text { Q1 } \\
2\end{array}$} & Speech & 0.357 & 0.721 \\
\hline & Spatial & 1.070 & 0.285 \\
\hline & Quality & 0.357 & 0.721 \\
\hline & Overall & 1.125 & 0.260 \\
\hline \multirow{5}{*}{$\begin{array}{l}\text { AP } \\
\text { S- } \\
\text { SS } \\
\text { D }\end{array}$} & Home & 1.529 & 0.126 \\
\hline & Work/School & 0.770 & 0.441 \\
\hline & Social & 2.090 & 0.037 \\
\hline & General & 2.666 & 0.008 \\
\hline & Overall & 1.886 & 0.059 \\
\hline
\end{tabular}

Table 4 Results of Wilcoxon signed rank statistic for speech intelligibility measurements in quiet and in noise. Grey shading indicates statistical significance.

\begin{tabular}{|c|c|c|c|c|c|c|}
\hline & \multicolumn{2}{|c|}{ quiet $(\mathrm{N}=8)$} & \multicolumn{2}{|c|}{$\operatorname{S}_{\text {CROS }}^{N_{C I}(N=}$} & \multicolumn{2}{|c|}{ So $N_{C l}(N=7)$} \\
\hline & $z$ & $\mathrm{p}$ & $\mathrm{Z}$ & $p$ & Z & $\mathrm{p}$ \\
\hline baseline & 2.380 & 0.017 & 2.366 & 0.018 & 2.197 & 0.028 \\
\hline 1 month & 2.380 & 0.017 & 2.366 & 0.018 & 2.028 & 0.043 \\
\hline 3 months & 2.521 & 0.011 & 2.366 & 0.018 & 2.366 & 0.018 \\
\hline
\end{tabular}




\section{Figure Captions}

Fig. 1 Subject responses to the APHAB (a) and SSQ12 (b) questionnaires and the experience portion of the APS-SSD (c) questionnaire. For APHAB and APS-SSD, lower scores indicate better performance while for the SSQ12, higher scores indicate better performance. Statistically significant differences are indicated by asterisks

Fig. 2 Subject responses to the satisfaction portion of the adapted APS-SSD questionnaire. Responses averaged across timepoints for each item (a) and responses averaged across items for each timepoint (b). Lower numbers indicate higher performance with a rating of 3 corresponding to 'neither satisfied not dissatisfied'

Fig. 3 Speech intelligibility performance in quiet in terms of speech recognition threshold measured in $\mathrm{dB}$ SPL at baseline, 1 month and 3 months. Lower numbers indicate better performance. Statistically significant differences are indicated by asterisks

Fig. 4 Speech intelligibility performance in noise in terms of speech reception threshold measured in $\mathrm{dB} S \mathrm{SNR}$ in $\mathrm{S}_{\mathrm{CROS}} \mathrm{N}_{\mathrm{CI}}$ (a) and $\mathrm{S}_{0} \mathrm{~N}_{\mathrm{Cl}}$ (b) at baseline, 1 month and 3 months. Lower numbers indicate better performance. Statistically significant differences are indicated by asterisks 